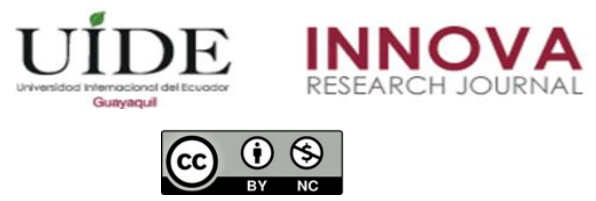

INNOVA Research Journal, ISSN 2477-9024

(Septiembre-Diciembre 2020). Vol. 5, No.3.2 pp. 151-162

DOI: https://doi.org/10.33890/innova.v5.n3.2.2020.1560

URL: http://revistas.uide.edu.ec/index.php/innova/index

Correo: innova@uide.edu.ec

\title{
Actividad turística y su relación con la gentrificación en el Centro Histórico de Quito
}

\section{Touristic activities and gentrification in the Historical Center of Quito}

\author{
María Soledad Oviedo Costales \\ https://orcid.org/0000-0002-8080-736X \\ Víctor Elías Llugsha Guijarro \\ (D) https://orcid.org/0000/0002-6894-9525 \\ Walter Omar Ocaña Zambrano \\ (D) https://orcid.org/0000/0002-0266-253X \\ Universidad UTE, Ecuador
}

Autor para correspondencia: sole_oviedo@hotmail.com; vikxox@gmail.com;

walter.ocanaz@gmail.com

Fecha de recepción: 21 de septiembre de 2020 - Fecha de aceptación: 18 de diciembre de 2020

\section{Resumen}

El Municipio del Distrito Metropolitano de Quito creó dos Zonas Especiales para el Turismo (ZET), a través de la ordenanza municipal No 236 del 2012, estableciéndolas en los espacios con mayor concentración de oferta turística: el Centro Histórico y el barrio de La Mariscal, con el fin de fomentar y promocionar la actividad turística de estas zonas, mediante un plan de gestión que regule las actividades en el territorio. En este marco, se realiza una investigación sobre gentrificación y turismo en el Centro Histórico de Quito, cuyo análisis se realiza a través de la revisión bibliográfica de distintas políticas de fomento de la actividad turística y del catastro de emprendimientos de servicios turísticos que son parte del sector, y su relación con la ocupación del suelo urbano en esta zona de la ciudad. Las razones para dicho análisis, residen en el hecho de que las políticas implementadas por el gobierno local, no parecen haber podido impedir los cambios significativos que trae consigo la actividad turística, sin afectar la calidad de vida de los habitantes tradicionales del Centro Histórico. Combinando información de tipo cualitativo y cuantitativo, se identificaron los planes y programas efectuados para dinamizar la actividad turística, y la evolución de emprendimientos relacionados con la prestación de servicios turísticos. A través de este estudio, se puede dimensionar de qué manera la actividad turística ha generado políticas y emprendimientos de alto nivel en la ZET Centro Histórico de Quito, y cómo estos han afectado a su población a través del desplazamiento.

Palabras claves: Centro Histórico; emprendimientos; gentrificación; planificación urbana; turismo urbano. 


\begin{abstract}
The Municipality of the Metropolitan District of Quito created two Special Zones for Tourism (ZET), through municipal ordinance No. 236 of 2012, establishing them in the areas with the greatest concentration of tourist offerings: The Historical Center and the neighborhood of La Mariscal, in order to encourage and promote tourist activity in these areas, through a management plan that regulates activities in the territory. Within this framework, we have researched about the relation between tourism and gentrification in the historic center of Quito. Through a bibliographic investigation about the policies of the municipality and the municipal land registry of touristic services, a new analysis was performed of the gentrification process in this important zone of the city. This new study was necessary because the policies implemented by local government have not been able to make significant changes to tourism in Quito, without affecting the quality of life of the traditional inhabitants of this zone. Combining both quantitative and qualitative information, we have identified plans and programs to energize touristic activities. Analysis of historic objectives and actions implemented demonstrates that some of the policies and touristic businesses have affected the population through displacement in the city's historic center.
\end{abstract}

Keywords: historical center; urban tourism; gentrification; heritage; urban planning.

\title{
Introducción
}

El interés por generar crecimiento económico ha llevado a las ciudades a una ávida competencia por atraer recursos e inversiones. Muchas de ellas han encontrado en el turismo una alternativa en esta época de globalización, siendo una actividad que, a partir de la revolución industrial, con el aparecimiento de las clases media y obrera en Europa, empezó su auge hasta llegar a lo que hoy en día se conoce como turismo de masas. El mercado turístico internacional ha ido creciendo sostenidamente, y el número de viajes internacionales a nivel mundial ha venido duplicándose aproximadamente cada 10 años (Organización Mundial del Turismo, 2008). Es así como las ciudades cada vez buscan más especializar su oferta de servicios, infraestructuras, y atractivos para fomentar su dinamización. Sin embargo, la actividad turística hasta el momento no ha logrado posicionarse como un estandarte del desarrollo sustentable, lamentablemente los sectores de población más desfavorecidos, en general han sido mantenidos al margen del crecimiento económico que puede generar el turismo (Cortés, 2013).

Salinas (2013) citando a Bromley y Mackie, (2009, p. 4) recuerda que varias ciudades latinoamericanas, poseen centros históricos llenos de riqueza cultural, que en algunos casos les ha permitido formar parte de la lista de Patrimonio Mundial de la UNESCO, con lo cual se ha facilitado la generación de proyectos de 'recuperación' o 'rescate' del patrimonio histórico. Esta recuperación busca generar espacios atractivos para el turismo y la inversión extranjera, por lo que se ha convertido en un producto de 'marketing urbano', como en los casos de algunas ciudades como Cuenca, Ecuador y Cusco, Perú (Steel y Klaufus, 2010). De esta manera, el centro de una ciudad, cuyo valor histórico patrimonial se destina al turismo, puede ser más propenso a experimentar gentrificación (Salinas, 2013). Esto, sin mencionar que, además, el turismo de masas ha provocado que en muchas ciudades se desvirtúen las características locales 
de las comunidades anfitrionas, comprometiendo el resguardo del patrimonio sociocultural que en un principio se busca conservar.

Dentro de este contexto, cabe analizar la situación del Centro Histórico de Quito -CHQ-. Con la creación del Distrito Metropolitano de Quito en 1996, la recuperación del centro histórico estuvo más vinculada con la dinamización económica a través de la actividad turística, tomando como ejemplos otras ciudades en donde esta visión empresarial había dado buenos resultados. Es así como se creó la Empresa del Centro Histórico, encargada de implementar planes para desarrollar acciones que incluyeran aspectos sociales y de reactivación económica (Del Pino, 2010). Las transformaciones que se han dado desde ese entonces, han provocado una renovación de la imagen del centro histórico a través de intervenciones en casas patrimoniales que se han convertido en hoteles, restaurantes, cafeterías, y lugares de entretenimiento y esparcimiento. De esta manera, en el núcleo central del centro histórico -especificado en el Plan Especial del Centro Histórico de Quito CHQ 2003 como las 54 hectáreas del centro histórico en donde, entre otras cosas, se concentran los atractivos turísticos- los lugares de vivienda han ido disminuyendo, dando paso a la generación de actividades administrativas y de servicios turísticos. Además, entre 2011 y 2014, el Gobierno Nacional del Ecuador planteó una serie de innovaciones en el Centro Histórico de Quito a través de la ejecución de un 'Plan de Revitalización Urbana' que buscaba realizar intervenciones emblemáticas a nivel de vivienda, equipamiento y espacio público -entendido como el escenario que tiene la función de albergar actividades de recreación y esparcimiento para la sociedad (Carrión, 2005); propiedades públicas, ejes viales, seguridad ciudadana, movilidad, turismo, entre otros. Con este plan, el Gobierno Nacional y el Municipio de Quito buscaban resolver los principales problemas, que a su juicio, aquejan al centro histórico, tales como mejorar las condiciones de vida de los pobladores de sectores que viven en condiciones de extrema pobreza, revertir el decrecimiento poblacional y el deterioro del patrimonio, y crear un mecanismo de gestión del centro histórico que involucre a todos sus actores, garantizando la conservación del patrimonio y el fomento de la actividad turística (Municipio del Distrito Metropolitano de Quito, 2012).

Este artículo analiza de qué manera las políticas implementadas en el centro histórico por parte del municipio, que han buscado reactivar económicamente la ciudad y atraer capital global invirtiendo grandes sumas de dinero -con el objetivo de 'embellecer' la imagen del centro de la ciudad- han generado externalidades negativas para la población de escasos ingresos; basándose en un enfoque teórico de conceptos, principios y criterios específicos sobre la gentrificación.

\section{Gentrificación como proceso derivado de la actividad turística}

El vocablo gentrificación, como se concibe actualmente, se refiere al desplazamiento de la población más vulnerable, generado por el aburguesamiento de sectores urbanos. Este concepto surge en la década de los sesenta, perfilado por Ruth Glass y utilizado para definir la invasión de varios barrios obreros en Londres, por parte de "individuos de clase media que rehabilitaban la deteriorada edificación residencial haciendo subir los precios de la vivienda y 
provocando la expulsión de las clases obreras que originalmente habían ocupado el sector" Glass citada en (Díaz, 2013). Por otra parte, para explorar lo que significa el término gentrificación, (Smith, 1996), lo define como el proceso mediante el cual los pobres y la clase proletaria del centro de las ciudades son desplazados de barrios que son remodelados a través de la inyección de capital privado de gente de clase media que llega a comprar casas en zonas que previamente estaban degradadas, razón por la cual los antiguos pobladores de clase media desocuparon el sector con anterioridad, concepto que puede ser considerado válido sobre todo en los Estados Unidos y Europa. El autor argumenta que la utilización de términos como revitalización, mejoramiento o 'renacimiento' de un barrio, supone que de alguna manera éstos se encontraban en un estado de desvitalización o de 'agonía cultural' previamente a la gentrificación, según asegura el autor, y que, si bien es el caso en ciertas situaciones, otras veces algunas comunidades de clase obrera muy vitales, son desvitalizadas culturalmente a través de la gentrificación, ya que tienen que desplazarse.

Según Smith (2011), citado en (Contreras, Lulle, y Figueroa, 2012), la gentrificación está transformando con claves 'clasistas' las ciudades de los Estados Unidos, causando el desplazamiento de los residentes originales de los barrios afectados y la pérdida de identidad y estilo de vida de estos lugares y, por lo mismo, suscitando el rechazo por parte de sus habitantes. Esta posición claramente plantea la expulsión como la causalidad de la gentrificación.

Sin embargo, en el contexto latinoamericano, algunos autores le brindan otro enfoque al mismo concepto, desligándolo de la idea de la expulsión como consecuencia del mismo. Según Sabatini, Vásquez, Robles y Rasse (2010), la esencia de la gentrificación yace, por el contrario, en la conexión de dos fenómenos: la invasión de una zona residencial por viviendas de hogares de mayor categoría social y, como consecuencia de lo anterior, la elevación generalizada de los precios del suelo. Esta es una aproximación conceptual que nos facilita una postura distinta, pero que siempre implica la llegada de 'nobles' asociada a personas de 'mayor' categoría social (Sabatini, Vásquez, Robles, y Rasse, 2010).

Para los autores (Janoschka y Casgrain, 2011), el concepto de gentrificación encierra ocultamente un significado ligado al pensamiento neoliberal y la forma de hacer ciudad desde este modelo económico. La utilización de términos como revitalización, rehabilitación, o renovación urbana, está vinculada al crecimiento económico de las urbes, lo que genera cada vez más diferencias sociales, confirmando el hecho de que las ciudades en la actualidad se construyen para satisfacer necesidades de los consumidores que tienen mayor poder adquisitivo. Afirman que la proliferación de políticas neoliberales en las ciudades contribuye a incrementar procesos de gentrificación cuya finalidad es la de estructurar el sistema económico bajo el sistema de propiedad privada, incluso haciendo uso de justificaciones como la de 'restaurar el patrimonio histórico de los centros de las ciudades', para que en definitiva este nuevo paisaje sea la atracción para turistas, élites y la clase media, generando la expulsión del comercio ambulante por ejemplo, siempre con el pretexto de 'mejorar el paisaje' para atraer a los grupos mencionados. Sostienen que el desarrollo de la gentrificación debe generar un movimiento de 
resistencia, de lucha de pobladores de escasos recursos para que puedan defender sus derechos de ciudadanos frente al avance de esta política neoliberal que finalmente lo que busca es desplazarlos con el único objetivo de generar rentabilidad económica, despojándolos de la posibilidad de vivir en el barrio que los vio crecer (donde medianamente garantizaban su 'reproducción social'), obligándolos a desplazarse a sectores donde no cuentan con servicios públicos como hospitales o colegios, ya que debido al alza de los precios del suelo, se ven en la imposibilidad de adquirir una propiedad en el sector.

Como se mencionó anteriormente, los autores (Sabatini, Vásquez, Robles, y Rasse, 2010), proponen que la gentrificación que se genera debido a intereses culturales de ciertos grupos de clase media, no puede ser explicada a través de los intereses de grupos inmobiliarios en generar rentabilidad económica. Según los autores, este tipo de gentrificadores están motivados por la conservación del patrimonio urbano, siendo atraídos por la diversidad del sector, es decir, son gentrificadores interesados en el 'valor de uso' del barrio, a diferencia de los promotores inmobiliarios que están interesados en el 'valor de cambio' que genera la gentrificación. Sustentan que, es posible entonces pensar en una 'gentrificación sin expulsión' en la que diversas clases sociales convivan, contribuyendo de esta manera a generar ciudades menos segregadas residencialmente hablando, a través de políticas que permitan reducir el riesgo de desplazamiento, y que incentiven inversiones en obras públicas que generen heterogeneidad en el territorio.

Por otra parte, y desde una visión un poco más acotada, (Delgadillo V. , 2010) define a la gentrificación como un fenómeno económico, político, cultural y social que consiste en la revalorización de barrios centrales deteriorados y habitados por grupos sociales de bajos ingresos que una vez rehabilitados se destinan a la residencia y al consumo de clases medias. El autor hace referencia a distintas clases de gentrificación, entre las que se encuentra la turistificación, definida como la transformación de barrios en enclaves destinados específicamente para turistas, en donde la vivienda popular se transforma en alojamientos, restaurantes, tiendas y otros servicios para el consumo del turista. Este tipo de gentrificación suele contener una fuerte participación de los gobiernos locales, quienes ven en el turismo una fuente de divisas económicas (Delgadillo V. , 2010). (Díaz, 2013), menciona que un centro histórico degradado puede convertirse en un espacio muy apetecido por la inversión privada, haciendo que la rehabilitación del mismo se enfoque en usos vinculados con la actividad turística.

En América Latina se han dado distintos puntos de vista sobre el término gentrificación, algunos autores como (Delgadillo V., 2005) o (Ward, 1993), sostienen que el proceso de gentrificación no se produce de la misma manera que en Estados Unidos o Europa, ya que existe una economía basada en servicios y producción artesanal en nuestros centros urbanos, por lo que la clase media no tiene interés de habitar estos espacios, y por otra parte la renta del suelo no es lo suficientemente atractiva para los inversionistas privados. Se puede decir que durante las últimas décadas, las ciudades latinoamericanas han tenido un ritmo acelerado de crecimiento, acompañado de regeneración en zonas centrales para vivienda, lo que generalmente conlleva 
procesos de gentrificación. En Buenos Aires por ejemplo, la gentrificación de ciertos barrios se vincula no solo con la generación de vivienda para sectores de clase media-alta, sino también con servicios subsidiarios relacionados con la cultura, el turismo, la educación, etc. En este sentido, el espacio preparado para el turismo, normalmente tiende a excluir a los antiguos habitantes, que van siendo desplazados (di Virgilio y Guevara, 2014).

Por otra parte, varias investigaciones sobre gentrificación en América Latina se desarrollan en áreas urbanas centrales o centros históricos, a través de autores como (Mongin, 2006) o (Choay, 2006), quienes manifiestan que muchos centros históricos se han convertido en un lujo del cual solo pueden disfrutar unos pocos, ya que se va convirtiendo en un espacio museificado, turistificado, y gentrificado, como método para revitalizarlo y salvarlo de la destrucción.

\section{Metodología}

Para determinar la relación entre la actividad turística y la gentrificación en el Centro Histórico de Quito, esta investigación combinó información de tipo cualitativo y cuantitativo que permitió identificar dichas relaciones a través de un análisis espacial, para el cual se utilizó la delimitación del 'núcleo central', que comprende 54 hectáreas del Centro Histórico de Quito, en donde se concentra la mayor parte de atractivos turísticos y servicios, como se puede observar en la ¡Error! No se encuentra el origen de la referencia..

\section{Figura 1}

Delimitación núcleo CHQ y establecimientos turísticos existentes. Fuente: Elaboración propia en base a Del Pino, 2010

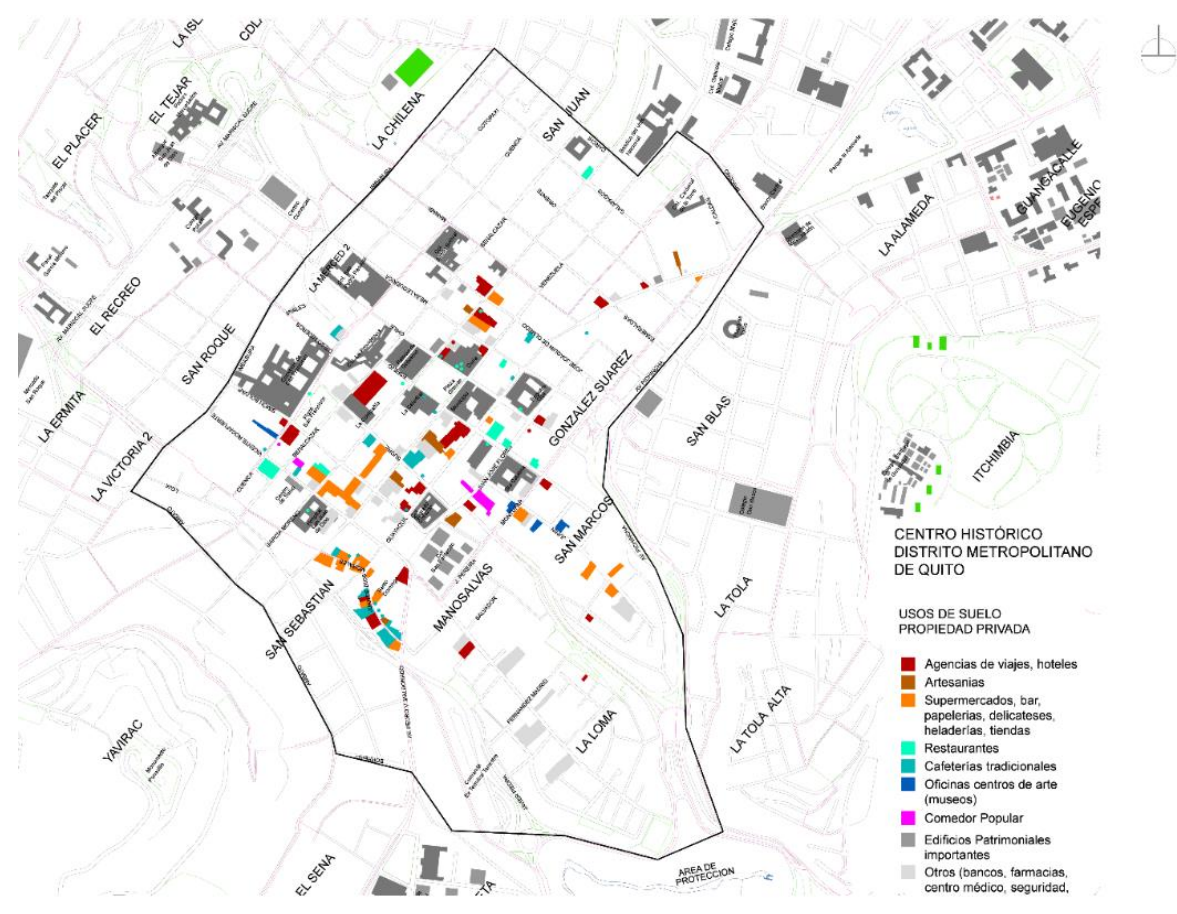


Por otro lado, se realizó una revisión de varios planes de intervención urbana implementados en el Centro Histórico de Quito, basándose en la necesidad de fomentar el turismo. Por otra parte, con el fin de determinar los cambios de uso del suelo vinculados con el turismo en el CHQ, se analizó el desarrollo histórico de la actividad turística a través del catastro anual de servicios turísticos del Ministerio de Turismo, así como la evolución de las inversiones inmobiliarias turísticas, a través del Registro de Actividades Turísticas de la Empresa Pública Metropolitana de Gestión de Destino Turístico. Se llevó a cabo un análisis documental bibliográfico, orientado a determinar los impactos causados por la actividad turística en la población del CHQ.

\section{Resultados}

Al ser el mayor conjunto patrimonial de América Latina, el Centro Histórico de Quito, con una superficie de 376 hectáreas, cuenta con 130 edificaciones monumentales y más de 5.000 inmuebles registrados como patrimonio histórico. Como resultado de un movimiento integrado por ciudadanos y autoridades locales, en 1978 fue declarado Patrimonio Cultural de la Humanidad por la UNESCO (Empresa Pública Metropolitana de Gestión de Destino Turístico, 2011).

Dicha declaratoria obligó a la ciudad a asumir su particularidad en un contexto universal al adquirir una proyección internacional inscrita en la dinámica global-local, donde la supervivencia de sus peculiaridades histórico-culturales locales forma parte de su inserción a nivel mundial (Carrión, 2005). Sin embargo, en términos prácticos, esta declaratoria sólo ha dinamizado el núcleo del centro histórico donde se concentran los principales atractivos, produciendo una fragmentación del espacio porque lo que sucede en la actualidad es que no es el ciudadano la razón del urbanismo o de la renovación en los centros históricos, el sujeto para el cual se diseña es el turista, el transeúnte. "Mientras existen 'áreas orientadas netamente a actividades turísticas', existe 'otra' ciudad que oculta, excluye y segrega a la pobreza del escenario turístico. Así, habría una coexistencia de dos realidades urbanas, una de frente abierta al turista y a las inversiones, y una de fondo que estaría ocultando las relaciones sociales de dominio y exclusión propias de las relaciones capitalistas de producción” (Ibarra, 2007, pág. 203).

La definición del Centro Histórico de Quito como clúster turístico por parte del municipio de la ciudad- entendiendo al clúster como el "conjunto de empresas e instituciones que a partir de la puesta en valor de los recursos turísticos interactúan en los destinos para satisfacer la demanda" (Varisco, 2007, pág. 31), es parte de una dinámica globalizadora en la ciudad, que se manifiesta además en lugares aledaños emblemáticos como el antiguo Hospital Eugenio Espejo, convertido en el actual Centro de Convenciones Eugenio Espejo, la estructura del antiguo mercado de Santa Clara, convertida en el Centro Cultural Itchimbía, o el antiguo Hospital Militar convertido en el Centro de Arte Contemporáneo de la ciudad. Desde la perspectiva del municipio, Quito desde el año 2003 es una ciudad renovada, que invita al turista y al inversionista extranjero. El haber sido designada como Capital Iberoamericana de la Cultura el año 2004, forma parte del reconocimiento internacional de este proceso de cambio de imagen, que defiende que una buena gestión de su patrimonio histórico, asociada con el interés común de 
mejorar la calidad de vida de sus pobladores, genera iniciativas de inversión local y por tanto se convierte en un modelo de desarrollo.

Otro de los reconocimientos que forma parte de esta visión de la ciudad es el 'Oscar del Turismo', al cual la ciudad de Quito se ha hecho acreedora por varias ocasiones desde el 2013 hasta la actualidad, consolidándose como uno de los destinos turísticos líderes en Sudamérica (Castellanos, 2015). Pero esta nueva imagen del Centro Histórico de Quito creada para los turistas, ha provocado también cambios notorios en la vida cotidiana, como se mencionó anteriormente. Muestra de ello, fue la reubicación gradual de 5.200 comerciantes en el año 2002. Los nuevos "Centros Comerciales del Ahorro" albergaron a estos comerciantes, siendo exitoso el desalojo de las calles, que fue negociado y programado en condiciones aceptables por las partes y que podría decirse, se realizó en forma pacífica sin llegar a confrontaciones mayores. A través de esta acción en concreto, se suprimió la presencia de los comerciantes informales en las calles del centro histórico, recuperando el espacio público; plazas, aceras y vías, lo que mejoró el tráfico y el acceso de usuarios y turistas. Se estima que, en este sector, compraban alrededor de 320 mil personas de escasos recursos en su mayoría. El 76.8 \% de las personas que compraba en el centro histórico, venía de otros sectores de la ciudad; el $42.5 \%$ desde el sur de la ciudad; el $30.6 \%$ del norte y el 3.7\% de fuera del Distrito Metropolitano de Quito. El número de comerciantes informales ubicados en el Centro Histórico de Quito en el año 1998 era aproximadamente de ocho mil, distribuidos en un espacio de 22 manzanas, un 80\% (6.400) desarrollaban sus actividades en el sector denominado "La Ipiales" y su entorno, establecidos en puestos fijos, de los cuales el $85 \%$ ocupaba espacios públicos y el $15 \%$ centros comerciales, y los restantes -1.600- estaban dispersos entre calles, plazas y esquinas del centro histórico (Granja, 2010).

Sin embargo, a partir del año 2009, con el cambio de administración del municipio y una nueva visión de uso del espacio público, los comerciantes volvieron paulatinamente a las calles del centro histórico, lo que se contradice con las acciones que se llevaron a cabo como parte del 'Plan de Revitalización del CHQ' implementado por el gobierno nacional entre 2012 y 2014. Alvarado (2015) asegura que las políticas públicas urbanas de la capital, consideradas como "propuestas de regulación pública de los múltiples problemas y contradicciones que afrontan las sociedades actuales" (Barenboim, 2012, pág. 31), han intentado reubicar a la población de ciertos barrios del centro histórico para proceder a la implantación de hoteles, y embajadas de varios países. En este sentido, "la expropiación se convertiría en el arma utilizada por la institucionalidad, para depurar estos espacios. Paz, (citado en Alvarado, 2015) relata que tras la pretensión de exclusión de los residentes de los inmuebles, declarando las viviendas bajo el apelativo de 'utilidad pública', se vulneraría el derecho a la propiedad privada y además, se propendería una acción en pro de la gentrificación" (Alvarado, 2015). Por otra parte, Paz señala que es importante "aclarar el papel que deben desarrollar la institucionalidad y los habitantes de las áreas céntricas, como rectores de la gestión e intervención que se realice en las centralidades, para mantener la preponderancia del uso del suelo residencial del centro histórico, sobre el uso del suelo comercial" (Paz, 2014, p. 19).

Desde otra perspectiva, según una investigación realizada por el Instituto de la Ciudad en 2012, las familias de estratos medios y medios altos presentes en el Centro Histórico de Quito, lo han ido abandonando poco a poco, ya que el costo de oportunidad social y económica de 
mantener una casa de vivienda o familiar, se eleva cada vez más. Si bien las familias de clase media se desplazan, hay familias de estratos medios bajos y bajos provenientes de otras ciudades o de sectores rurales que hacen del CHQ su lugar de vivienda a pesar de que muchas veces tienen que vivir en situación de tugurización, es decir, de hacinamiento provocado por la ocupación paulatina de espacios abandonados por parte de las clases sociales más desfavorecidas. Aun si se produce este fenómeno, el centro histórico se desocupa, mientras el resto de la ciudad tiende a densificarse (Municipio del Distrito Metropolitano de Quito, 2012).

Si a este hecho se agrega el fenómeno de elitización que sufre el CHQ con la llegada de la actividad turística, tenemos como resultado la gentrificación de ciertos espacios en el núcleo del centro histórico donde se concentran los servicios turísticos. (Del Pino, 2010), manifiesta que en 1990 la población del Centro Histórico de Quito fue de 81.384 habitantes, y 20 años después se redujo a 40.913. Para ejemplificar, las cifras censales de 1990 y 2010 avalan este dato, tal como se grafica en la ¡Error! No se encuentra el origen de la referencia..

\section{Figura 2}

Evolución del despoblamiento en barrios del CHQ entre 1990 y 2010. Fuente: Instituto de la Ciudad, 2014

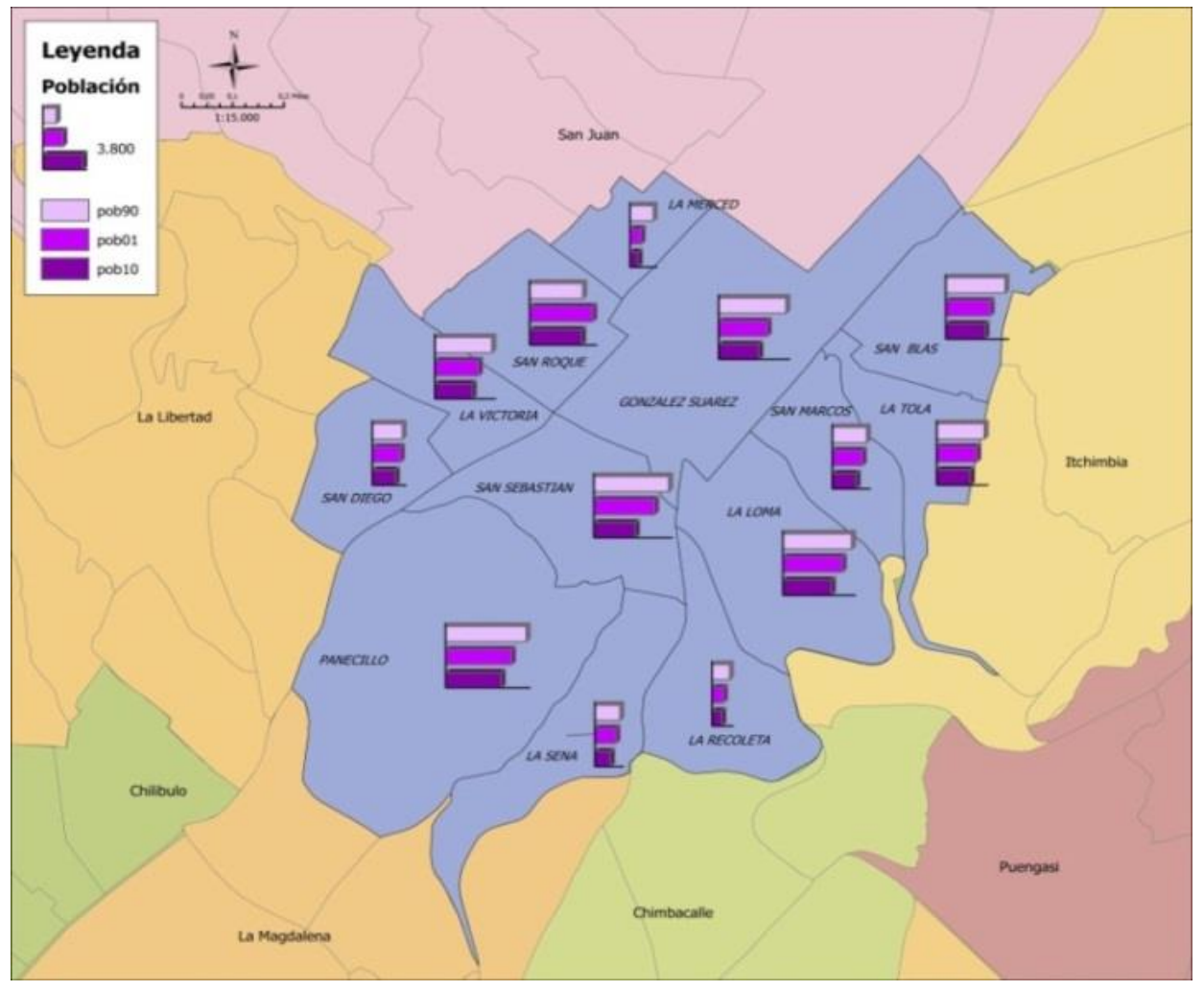

Algunos barrios que conforman el núcleo del CHQ, como González Suárez y San Sebastián -en parte- se han ido despoblando paulatinamente debido a varios factores, entre ellos 
la no realización de mantenimiento de la vivienda en casas patrimoniales, que ha producido el fenómeno de tugurización, y por otra parte, la elevación de precios de alquiler en las viviendas patrimoniales recuperadas como parte de los distintos planes emprendidos por el Municipio de Quito (Oviedo, 2014).

Si bien en 1978 Quito fue designada Patrimonio Cultural de la Humanidad, a lo que contribuyó decisivamente su espectacular centro colonial, con una enorme densidad de edificios patrimoniales, desde entonces, especialmente en las dos últimas administraciones municipales, se han generado planes para activar turísticamente el CHQ, con acciones que han ido desde la 'reubicación' del comercio informal, la subterranización de basura (desapareciendo con ello los recicladores), la turistificación de sectores específicos como la calle La Ronda (Llugsha, 2019), o los intentos porque vuelvan las clases altas a habitar el centro con la construcción de lugares hipersegurizados como en el barrio de San Marcos. Ello conjugado con una nueva política del espacio público, que incluye arte nocturno y la creación de una policía turística, ha ido entretejiendo una tensión continua entre el centro histórico de los habitantes y el centro histórico de los visitantes (Bayón, 2014).

\section{Conclusiones}

Las políticas aplicadas para fomentar la actividad turística en el CHQ han tendido continuamente hacia esquemas neoliberales de manejo de grupos sociales, buscando favorecer por sobre todo el 'crecimiento económico orientado al mercado', consolidando el modelo capitalista que da mayor importancia al valor de cambio y ve al patrimonio como capital físico. En ese sentido, turismo y sector inmobiliario juegan un rol preponderante en este sistema, siendo los mayores beneficiarios económicos de las acciones tomadas para fortalecer un turismo de élite. Si bien estas políticas de recuperación del patrimonio material han permitido que la actividad turística vaya en aumento, lo cual desde el punto de vista económico es favorecedor para la ciudad, la tendencia hacia la elitización y la monofuncionalización turística de ciertos espacios en el núcleo, implica de un lado, la segregación de sectores populares que se ven marginados de las posibilidades de acceso a los bienes inmuebles por su escaso poder adquisitivo, y, de otro lado, la escasa participación de los residentes tradicionales en la toma de decisiones medulares sobre su espacio. Todo esto, en consecuencia, afecta a la calidad de vida de los habitantes. Cabe señalar que, con la llegada de la pandemia en el 2020, toda actividad turística en el Centro Histórico de Quito se ha visto amenazada con desaparecer. Para determinar si los efectos la etilización continuarán siendo un impacto negativo para los habitantes del Centro Histórico de Quito post pandemia, habrá que esperar a la recuperación del sector, que dependerá de las medidas que se tomen para retomar la actividad turística a través de un modelo sostenible que permita la inclusión de la comunidad local en las decisiones que se tomen para favorecer la dinamización económica del espacio.

Frente a esta situación, se corre el riesgo de perder el dinamismo tradicional del barrio, en nombre de fomentar aquello que rinde réditos económicos porque resulta atractivo para los turistas, sin que sean necesariamente actividades tradicionales del lugar, que nos particulares y parte de la vida cotidiana de sus habitantes. 


\section{Referencias bibliográficas}

Alvarado, K. (diciembre de 2015). Revista Planeo, $N^{\circ} 25$. Obtenido de http://revistaplaneo.uc.cl/ Barenboim, C. (2012). Políticas públicas urbanas e instrumentos de regulación en la ciudad de Rosario. Revista Iberoamericana de Urbanismo, 31-41.

Bayón, M. (2014). Derecho a la ciudad en el centro histórico de Quito? El canelazo de la ciudad, $15-18$.

Carrión, F. (2005). El centro histórico como objeto de deseo. En F. Carrión, \& L. (. Hanley, Regeneración y revitalización urbana en las Américas: hacia un Estado estable (págs. 3557). Quito: Flacso, sede Ecuador.

Carrión, F. (2005). Los centros históricos en la era digital en América Latina. Espacios, flujo, representación. En ITESO, Ciudades translocales (págs. 85-108).

Carrión, F. (2014). Urbicidio o la producción del olvido. Monografías VP. Facultad de Arquitectura, Universidad de la República, Uruguay, 15-29.

Castellanos, G. (noviembre de 2015). El Comercio. Obtenido de http://www.elcomercio.com/actualidad/quito-destino-lider-sudamerica-world.html

Choay, F. (2006). Le règne de l'urban et la mort de la ville. Pour une Anthropologie de l'Espace, 165-198.

Contreras, Y., Lulle, T., \& Figueroa, O. (2012). ¿Gentrificación en áreas centrales latinoamericanas: un fenómeno de cambio socio-espacial relevante? Contreras, Y.; Lulle, T. y Figueroa, O. (2012). ¿Gentrificación en áreas centrales latinoamericanas:Universidad de Externado Colombia, y Programa de Doctorado de la Pontificia Universidad Católica de Chile.

Cortés, M. (2013). Desarrollo urbano y turismo sustentable. Potencial para revertir los grandes problemas de las ciudades medias y pequeñas. . Cortés, M. (2013). Desarrollo urbano y turismo sustentable. Potencial para revertir los granRevista Topofilia, Vol. IV, no. 1, enero. Centro de Estudios de América del Norte. El Colegio de Sonora.

Del Pino, I. (2010). Centro Histórico de Quito. Una centralidad urbana hacia el turismo. Quito: FLACSO.

Delgadillo, V. (2005). Centros históricos de América Latina, riqueza patrimonial y pobreza social: la rehabilitación de vivienda en Buenos Aires, México y Quito, 1990-2003. Mexico: tesis Doctoral.

Delgadillo, V. (2010). Aburguesamiento de barrios centrales, un proceso en expansión y mutación. . Revista Economía, Sociedad y Territorio, vol. x, no. 34., 835-846.

di Virgilio, M., \& Guevara, T. (2014). Gentrificación liderada por el Estado y empresarialismo urbano en la Ciudad Autónoma de Buenos Aires. Coloquio Internacional Perspectivas del Estudio de la Gentrificación en México y Latinoamérica (págs. 31-52). México DF: UNAM.

Díaz, I. (2013). La gentrificación en la cambiante estructura socioespacial de la ciudad. Revista bibliográfica de Geografía y Ciencias Sociales.

Empresa Pública Metropolitana de Gestión de Destino Turístico. (2011). Guía Turística Experimenta Quito.

Granja, Á. (2010). Análisis de la situación de los comerciantes informales del Centro Histórico de Quito, después de su reubicación en los centros comerciales del ahorro, vista desde la perspectiva de los propios comerciantes. Quito: FLACSO Tesis.

Esta obra se comparte bajo la licencia Creative Common Atribución-No Comercial 4.0 International (CC BY-NC 4.0) 
Ibarra, R. (2007). Segregación socio-espacial en ciudades turísticas: El caso de Canela (RS), Brasil. Revista Estudios y perspectivas en Turismo, vol. 16, 195-215.

Janoschka, M., \& Casgrain, A. (2011). Urbanismo Neoliberal y Gentrificación en Santiago de Chile; Diálogos entre Teoría Urbana y reivindicación vecinal. Santiago de Chile: Proyecto NEOLIBERAL_CITI: "Re-framing urban neoliberalism and neo-liberal citizenship Enactments of resistance and practices of protest".

Llugsha, V. (2019). La ciudad de las oportunidades. Turistificación y emprendimientos del Centro Histórico de Quito. INNOVA Research Journal, 223-232.

Mongin, O. (2006). La condición urbana, la ciudad a la hora de la mundialización. Buenos Aires: Paidós.

Municipio del Distrito Metropolitano de Quito. (2012). El Centro Histórico: algo más que un centro turístico. Boletin No. 12 Instituto de la Ciudad, 12B.

Municipio del Distrito Metropolitano de Quito. (24 de Septiembre de 2012). Taller "El Centro Histórico de Quito contemporáneo". Quito, Pichincha, Ecuador.

Organización Mundial del Turismo. (2008). Introducción al Turismo. Mexico: Editorial Patria.

Oviedo, S. (2014). Centro histórico de Quito: Cambios en la configuración residencial y usos de suelo urbano asociados al turismo. Santiago de Chile: Tesis de Magister. Pontifica Universidad Católica de Chile.

Paz, J. (2014). La gestión de los centros históricos: globalización, turismo, hábitat, y patrimonio cultural. El canelazo de la ciudad, 19-29.

Sabatini, F., Vásquez, H., Robles, S., \& Rasse, A. (2010). Sabatini, Francisco; VásquezGentrificación sin expulsión, fuerza de transformación de las ciudades latinoamericanas: datos e interpretación para Santiago. Santiago de Chile: Instituto de Censo, Pontifica Universidad Católica de Chile.

Salinas, L. A. (2013). Gentrificación en la ciudad latinoamericana. El caso de Buenos Aires y Ciudad de México. . Revista Digital Geographos, vol. 4, no. 44. Universidad Nacional Autónoma de México.

Smith, N. (1996). The New Urban Frontier: Gentrification and the Revanchist. Editorial Routledge.

Varisco, C. (2007). Iniciativas de desarrollo local y fomento del clúster turístico. Aportes y Transferencias, 31-42.

Ward, P. (1993). The Latin American inner city: differences of degree or of kind? Environment and planning, 1131-1160. 